\title{
Climate change and the economics of the world's fisheries: an introduction
}

\author{
Manuel Barange, Rögnvaldur Hannesson and \\ Samuel F. Herrick Jr
}

When the public, media and politicians talk about climate change, they mostly have in mind changes in weather patterns, impacts on agricultural production and disruptions in supporting energy systems. Yet climate change will affect, and in some cases already is affecting, the dynamics of all components of the earth's system. Climate change is not an isolated phenomenon, but just one dimension of an increasingly evident human imprint on the earth at a global level, which affects climate, land use, resource exploitation and pollution, among other issues. Many of these issues are linked through positive feedbacks that increase their impacts. Therefore, we often refer to 'global change' rather than 'climate change', in acknowledgement of the links between the physical, chemical and biological systems that regulate the earth and the social systems that it supports.

Global change research in the marine ecosystem is a fairly new scientific discipline. Some of its components, like eutrophication and overfishing, are well known, while others, such as climate impacts, are poorly understood. However, there is increasing recognition that global change is affecting the ecological structure and functioning of the marine ecosystem, and the goods and services it provides, in similar ways to the better known terrestrial ecosystems (Barange, 2002).

The Global Ocean Ecosystem Dynamics programme (GLOBEC) was created in 1999 by the Scientific Committee on Oceanic Research (SCOR), the Intergovernmental Oceanographic Commission of UNESCO (IOC) and the International Geosphere-Biosphere Programme (IGBP), to understand how global change will affect the abundance, diversity and productivity of marine populations. This understanding is essential if we are to manage fish and shellfish populations effectively during this period of increased human impact and dependence on these resources. 
GLOBEC has implemented a number of national, multinational and regional programmes in pursuit of its objectives (GLOBEC, 1999). One such regional effort is the Small Pelagic Fish and Climate Change Programme (SPACC). SPACC was tasked with the long-range goal of forecasting how changes in ocean climate would alter the productivity of small pelagic fish populations (anchovy, sardine, herring, and so on) in key areas of the world's oceans. Small pelagic fish were selected because they constitute about 30 per cent of the world's fish catch, have a global distribution, and are characterized by dramatic abundance fluctuations in response to ocean climate. Some of these fluctuations are synchronic in nature (Schwartzlose et al., 1999). One of the intentions of SPACC is to assess how climate variability and change will affect the economics of small pelagic fisheries.

Until now, research on the economic implications of climate change on fisheries has been limited and fragmented. In general, countries adjust to changes in the abundance of pelagic fish, regardless of the cause, at highly variable time scales and in an uncoordinated manner. It therefore seemed appropriate for SPACC to convene a workshop to investigate what has been learned from the economic consequences of these variations and adjustments in the recent past, with the objective of taking on board some lessons on how to adapt and respond to future climate changes, and perhaps also to set the research agenda to be followed.

The workshop took place in Portsmouth, hosted by the Centre for the Economics and Management of Aquatic Resources (CEMARE) of the University of Portsmouth, UK. Those involved in organizing the workshop quickly realized that little research had been undertaken on this topic. This could hardly be due to widespread indifference about climate change, but rather because of the great uncertainty regarding the predictability of such effects, in comparison with pressing shorter-term issues such as fishing effort controls or stock recovery plans, for example. People could be understandably reluctant to address unpredictable events whose consequences were also equally unpredictable. Yet the participants soon learned that climate change and climate variability are two sides of the same coin. Climate variability has already had major economic consequences, and the interest in dealing with it and avoiding serious economic consequences is the same as that which requires us to understand climate change impacts.

This volume groups ten case studies that range from historical fluctuations of Atlanto-Scandian herring and their impacts, to management adaptations to possible regime shifts; from the differential consequences of pelagic fisheries collapses in Southeast Asia to the globalized nature of fishmeal markets. The case studies are complementary and yet self-standing, highlighting the need for a more coordinated assessment of 
impacts, and calling for more focused research. While this volume may not provide detailed solutions to global problems of growing concern, it aims to enthuse practitioners to embark on research in an area intimately linked to the sustainability of our marine resources at a time when pressures on them appear to be greater than ever.

\section{REFERENCES}

Barange, M. (2002), 'Influence of climate variability and change on the structure, dynamics and exploitation of marine ecosystems', Issues in Environmental Science and Technology, 17, 57-82.

GLOBEC (1999), Global Ocean Ecosystem Dynamics Implementation Plan, GLOBEC Report 13 and IGBP Report 47, Stockholm: IGBP

Schwartzlose, R.A., J. Alheit, A. Bakun, T.R. Baumgartner, R. Cloete, R.J.M. Crawford, W.J. Fletcher, Y. Green-Ruiz, E. Hagen, T. Kawasaki, D. Lluch-Belda, S.E. Lluch-Cota, A.D. MacCall, Y. Matsuura, M.O. Nevárez-Martínez, R.H. Parrish, C. Roy, R. Serra, K.V. Shust, M.N. Ward and J.Z. Zuzunaga (1999), 'Worldwide large-scale fluctuations of sardine and anchovy populations', South African Journal of Marine Science, 21, 289-347. 
Manuel Barange, Rögnvaldur Hannesson, and Samuel F. Herrick - 9781845428846 Downloaded from PubFactory at 04/26/2023 11:46: $00 \mathrm{AM}$ via free access 